\title{
KARL NIEDERHUT - EIN BEITRAG ZUR \\ DEUTSCH-BRASILIANISCHEN LITERATUR
}

\author{
REINALDO BOSSMANN
}

Im Alter von 91 Jahren ist Karl Niederhut am 29. April dieses Jahres in Pôrto Alegre gestorben. Mit seinem Ableben hat das deutsch-brasilianische Schrifttum einen seiner populärsten Repräsentanten verloren, die "Brasil-Post" einen ihrer eifrigsten Mitarbeiter, der unermüdlich durch Wort und Tat um diese Zeitung bemüht war. Den Lesern dieses Wochenblattes ist der weise Alte zum Begriff geworden, der mit seinen vielseitigen Beiträgen Humor und Trosł spendete, gütige Ratschläge erteilte, das Tagesgeschehen kritisch beleuchtete, den fierischen Ernst belächelte und nur den Wunsch hatte, in dieser ruheund gemütslosen Zeit etwas Freude und Erbauung in die Herzen zu träufeln.

Bis vor wenigen Jahren war Niederhut ganz und gar der Schriftstellerei verbunden. Ein schwerer Unfall und Krankenlager liessen ihn zwar publizistisch versfummen, doch zeigte er bis zu seinem 90 . Geburtstag für alles, was auf dem Erdenrund geschah, lebhaftes Interesse - zum Erstaunen der zahlreichen Freunde, die ihn an seinem Ehrentage umgaben.

Grosse Ehrungen sind ihm während seines arbeitsreichen Lebens nie zuteil geworden. Er wusste um seine unzeitgemässe Bescheidenheit, misstraute jedem Wirbel um Publizität, erkannte die Unzulänglichkeit amtlicher Stellen und privater Institutionen, um ein verdienstvolles Schaffen zu fördern. Trotzdem hat Niederhut nie resigniert und war unverdrossen, im Glauben an seine Sendung, tätig. Jede Woche erschienen seine Artikel, seine Gedichte in der "Brasil-Post"(1). Seine Beiträge wurden auch in fast allen deutschsprachigen Zeitschriften und Kalendern Südamerikas veröffentlicht, nicht nur unter seinem Namen, sondern auch unter den Pseudonymen Ernst Froh und Karl Friedmund. Sein Festspiel (1924) zur Jahrhundertfeier der deutschen Einwanderung(2) wurde auf mehr als 20 Vereinsbühnen aufgeführt, sein Drama "Die Prophetin von Ferra Braz" ging in die Geschichte des Staates Rio Grande do Sul ein. Es wendet sich gegen

(1) Semanário Brasileiro, im 20. Jahrgang, Verlagsort Săo Paulc.

(2) am 25. Juli 1824 in São Lecpoldo, Rio Grande do Sul. 
Aberglauben, Unvernunft, Hetze, Brutalitäł und ruft zur Besinnung, Vernunft, Frieden und Toleranz auf. Beide Werke wurden auch gedruckt und sind längst vergriffen. Während seiner letzten Lebensjahre hat er an einem umfangreichen Roman gearbeitet, dessen zentrale Themen die Indianer und Kolonisationsgeschichte Südamerikas sind.

Das Werk des Schriftstellers und Dichters Niederhut lässt sich nur verstreut auffinden. Zu einer Gesamt- oder Teilausgabe hat er es leider nicht gebracht. Sein Wunsch war, wenigstens seine Spruchdichtung in einem Bändchen vereint und veröffentlicht zu sehen. Doch auch dieses blieb nur Wunsch und Gedanke. Dazu schrieb er mir einmal: "Ich hätte allen Grund mit meinem Leben höchst unzufrieden zu sein, denn ich habe fast nichts von dem erreicht, was ich wollte. Nach diesem Lande kam ich vor allem in dem Glauben, hier Ruhe und Sammlug zu finden, kleine und grosse Geschichten und Theaterstükke wollte ich schreiben; statt dessen kamen Kinder angepurzelt, eins, zwei, drei, vier und damit die ständige Forderung des Tages. So ging das Leben dahin! Endresultat: Ich handle heute noch mit Anzeigen, von denen man nicht einmal weiss, ob sie wieder das einbringen, was die Leute dafür ausgeben. Gern hätte ich ja nun im Alter wenigstens eine Sammlung meiner besten Gedichte und Prosasachen zusammengestellt. Aber woher sollte ich wohl die Zeit zur Auslese nehmen und was sonst noch damit zusammenhängt? Und das Geld, die Kosten, die kaum wiederhereinkommen! Soll ich deswegen unglücklich oder verbittert sein? Fällt mir nicht im Traume ein! Wir können ja dem lieben Gott gar nicht dankbar genug sein, dass er uns hier wieder mit allem versehen hat, überreichlich, was wir brauchen. Alles aus eigener Kraft mit Gottes Hilfe."

Karl Niederhut hat viel geschrieben(3); doch über ihn ist wenig geschrieben worden. Die Anlässe dazu waren meistens die Etappen seines langen Lebens. Zu seinem 75. Geburtstage versuchte ich, diesen Menschen und Dichter, sein Wesen zu erfassen und seine Dichtung zu bestimmen(4). Ich leitete damals meine Skizze über ihn mit einem Ausspruch Erich Kästners ein: Er schreibt, wie er lebt, weil er lebt, wie er schreibt. "Und weiter standen die Sätze: "In der ehrwürdigen Hülle, mit schneeweissem Haar, gütigen und verträumten Augen, ist er innerlich ein lyrischer Jüngling geblieben, heiteren Gemüts, immer Freude spendend, von starkem Gottvertraven, träumerisch, vom Schönem und Edlen im Menschen beglückt, mit einem mil-

(3) Sinnsprüche, Gedichte, Erzählungen und viele Zeitungsartikel. Es ist hier unmöglich, all seine Prosaschriften zu nennen. Besonders zahlreich sind seine "Altragbetrachtungen", die die verschiedensten Gebiete behandeln.

(4) R. Bossmann: "Ein Dichterporträt: Carl Niederhut". In: Deutscho Nachrichten, Säo Paulo, vom 14./15. November 1954. 
den Lächeln an der menschlichen Gesellschaft herumkritisierend, ist er von Haus aus hannoveranisch, im Wesen althannoveranisch. Trotz seiner träumerischen Veranlagung, nach einem beschaulichen Leben tendierend, für die Schönheiten der Gottesnatur empfänglich, ha† er nie den praktischen Sinn für das tägliche Leben verloren. Sein gesunder Menschenverstand erlaubte ihm immer eine klare Beurteilung und logische Erfassung der Realitäten des menschlichen Daseins".

Der Hannoveraner Niederhut kam im Jahre 1913 nach Brasilien und war zunächst im Staate São Paulo als Lehrer tätig. Nach dem 1. Weltkrieg übersiedelte er nach Rio Grande do Sul und arbeitete als Schriftleiter der "Deutschen Post"(5) in São Leopoldo. Später wurde er in Pôrto Alegre sesshaft und verschrieb sich, neben kommerzieller Arbeit, dem Gedeihen deutscher Zeitschriften und Zeitungen. Nicht gesegnet an irdischen Gütern, in der vollen Erkenntnis, dass Mäzene hier rar gesät sind, ging er den gebirgigen Weg als Schriftsteller, verbunden dem Deutschtum in Brasilien, dem immer seine Liebe gehörte.

Niederhut, der an die Heilkräfte der Natur(6) glaubte, sagte einmal, dass jeder mit Erreichung des 50 . Lebensjahres sein eigener Arzt und Priester sein solle. Er war weder Protestant noch Katholik, vielleicht war er Brahmane. Und in der Tat ist er schon in der Jugend durch die indische Philosophie und den Buddhismus zum besseren Verständnis des Christentums gelangt, aber ohne Dogmen und Glaubensbekenntnisse. Der Frage, ob Christus Gottessohn war, mass er keine Wichtigkeit bei, wichtiger war für ihn die Nachfolge Christi. Die Bibel las er gern als Quelle köstlicher Wahrheiten. Denken und Empfinden betrachtete er als das Wichtigste im Menschen. Die Erlangung wahren Menschentums setze eine stete Übung voraus, die Gedanken zu beherrschen und zu bestimmen. Hohe Gedanken sind ein ständiges Gebet, die ureigene Tätigkeit des Menschen und die beste Vorbereitung auf ein höheres Leben. Das Praktizieren der Nachstenliebe und das Zeigen eines guten Willens waren ihm Gebote. Das "Liebe deinen Nächsten wie dich selbst" interpretierte er so, dass es viel leichter sei, die uns ferner Stehenden zu lieben, viel schwerer dagegen diejenigen, die uns täglich umgeben, uns schon zur Gewohnheit geworden sind, mit allen Schwächen und Eigenarten. Das Verhältnis zu ihnen fordere von uns immer wieder eine neue Anpassung, bedingt durch die jeweilige Situation, und setze auf beiden Seiten viel guten Willens voraus.

Die vier Grundpfeiler des Lebens sah er in Glaube, Güte, Glück

(5) Gegründet 1881, eingegangen 1928.

(6) Im Briefkasten der "Brasil-Post" gab Niederhut Ratschläge über die Anwendung von Hausmitteln und Kräutern gegen die verschiedensten Krankheiten. 
und Gesundheit. Sie kehren auch häufig in seiner Spruchdichtung wieder, die man unter dem Zyklus "Fröhliche Lebenskunst" vereinen kann. "Seine Sinnsprüche sind ernst-heiterer Natur, oft mit einem satirisch-humoristischen Unterton, nach Art von Erich Kästner, Joachim Ringelnatz und Wilhelm Busch"(7).

Die ewigen Kräfte wollen,

Dass wir uns freuen.

.1 .

Ja, die Freude schwingt dich hoch über alles Leid,

Freude ist der Widerhall aus der Ewigkeit.

.1 .

Freude ist nicht Ernte nur,

Freude ist auch Saat,

Freude ist nicht nur Genuss,

Freude ist auch Tat.

.1 .

Behalte freudig im Gedächtnis

Erinnerungen, die beglücken,

Hijlle alle in Vergessnis,

die dich betrüben und bedrücken.

. 1 .

Mürrisch und stumm

Macht alt und krumm.

Froh und heiter

Ist gescheiter.

.1 .

Lass im Sumpf die Frösche quaken,

Lass die Gassenhunde bellen.

Geh pfeifend deinen Weg

Zum Wanderziel, dem hellen.

.l.

Schliess dich nicht vom Leben aus,

Geht's auch oft in Saus und Braus.

Bedenke: Mancher stumme Denker

Wurde schon zum dummen Slänker. .1 .

Schau der Zukunft ins Gesicht,

Was du erlebt, erzähl es nicht.

Ist dein Weg mal nicht voll Licht,

Geh mit dir nur ins Gericht.

Tue ruhig deine Pflicht,

(7) R. Bissmann, a.a.O. 
Nimm den Lasten ihr Gewicht.

Glaub nicht alles, was man spricht,

Und vor allem grüble nicht.

.$/$.

Der Mensch liebt die Geselligkeit,

Den frohen Gast zu rechten Zeit,

Den Freundeskreis zu edler Rast -

Wohl dir, wenn du gefunden hast!

Doch sei nicht traurig, wenn er fehle,

Die Einsamkeit ist keine Last,

Du ladest einfach deine Seele

Dir wieder einmal ein zu Gast.

.1 .

Des Schicksals Tücke will mich unterkriegen?

Will Sieger sein im Brechen oder Biegen?

Ich sage nur: Potzbombenelement,

Zum Ärgern hab ich einfach kein Talent.

.1.

Gott gab uns immer Lohn genug,

Viel Erdenglück ward uns beschieden.

Und klappt er zu mein Lebensbuch,

So hoff ich nur auf Seelenfrieden.

.1 .

Das wahre Glücklichsein ist Pflicht,

Du musst nur wollen, immer wollen.

Sag ade dem Murren und dem Grollen,

Auch du schaust ungern in ein Brummgesicht.

Die Lyrik Niederhuts schlägt vielfältige Themen und Töne an. Ihre polaren Strukturelemente im Bildgefüge sind oft Gott - Mensch, Mensch - Gott, Mensch - Natur, ihre seelische Grundhaltung sind vorwiegend Freude, Schmerz und Dankbarkeit. Für ihn ist die Lyrik ständiges Gebet und Danksagung an den Schöpfer allen Seins.

\section{Abend-Segnung}

Ruhet aus! Des Abends Frieden Ist der Welt von Gott geschenkt. Horchet auf! Er hat den Müden Sich in jedes Herz gesenkt.

Drunten ruht im Arm der Wiesen

Blau und still der kleine See, Lautlos stehn des Waldes Riesen, Aus der Lichtung lugt ein Reh. 
Abendglanz vergoldet schöne

Hohe Wolken purpurgluh,

Ferne klingen Glockentöne,

Kirchenglocken: Abendruh.

Stille steh ich, um zu lauschen

Auf des Abends Feierlied, Und ich fühle leises Rausches, Als wenn Gott vorüberzieht.

\section{Ergriffenheit}

Wir gehen staunend durch die weite Welt. Weisst du es noch, wie du der Sonne Licht Zum ersten Male in dich eingezogen?

Du stauntest nur, jedoch du fragtest nicht.

Als sich des Hauses und des Gartens Tore Weit öffneten vor deinen kleinen Schritten, Da warst du selig in den Kinderträumen Und konntest danken nur, im Dank nur bitten.

Wie stauntest du, als hohe Tempeltüren Des Waldes und der trauten Wiesenflur, Der hellen Schule und des stillen Domes Sich vor dir öffneten - du stauntest nur.

So öffnen sich stets neue Tempelpforten, Zur Gotteswelt und zu den Menschenherzen.

Im Glück und Schmerz kannst nur die Hände falten Und staunend stehn vor jeder neven Welt Und zitlernd sehn der Seele Wunderkerzen.

\section{Das eine Wort}

Umkränzł von Sonnenhügeln, Im schönen Wiesental, Blüht meines Liebchens Garten Voll Rosen, sonder Zahl.

Und als das Mondlicht helle lag über Wald und Flur, Da ging ich still vorüber Und suchte eine Spur... 
Die dunkelste der Rosen,

Die hab ich abgebrochen.

Still presst' ich sie ans Herz

Und hab ein Wort gesprochen.

Nun singt und klingt dies Wort

In Liebchens Busen wieder,

Nun singt ihr roter Mund

Der Sehnsucht Liebeslieder.

Und wieder - wenn der Vollmond glänzt, Will ich sie etwas fragen,

Dann wird, von Rosen hold umringt,

Das eine Wort sie sagen.

\section{Ein Traum}

In einen alten, kühlen Brunnen Hat sich ein Blütenbaum geneigt Und ihm in stillverschwiegnen Stunden

Der Zweige Blütenpracht gezeigt.

Nun sah auf stillgewordenem Wasser

Er auch des Himmels Widerschein,

Des Domes Blau, die Silberwolken

Und nachts die tausend Sternelein.

Doch war es nur ein kurzes Träumen. Es kam ein Mensch in schnellem Lauf, der schaute murrend in den Brunnen Und stülpte einen Deckel drauf.

So ist es immer ja gewesen:

Die Ärmsten, die im Schatten stehn, Sie dürfen höchstens einmal träumen Von wonnevollen Blütenbäumen, Von Wolken, die zur Sonne gehn...

\section{Der Alltag}

Im sel'gen Nichtstun ehrt der Christ

Den lieben Sonntag, wie's sich schickt.

Sogar im harten Kirchenstuhl

Ist er schon oftmals eingenickt, da auch das Sitzen und das Hören Ja noch zur Arbeitslast gehören. 
Doch erst zur Woche von sechs Tagen

Muss man sich recht mit Pflichten plagen.

Da wird manch Stündlein "umgebracht"

Und auch die Predigt wohl verlacht.

Nur gut, dass kein Gebol gegeben,

Wie wir im Alliag sollen leben.

So kann man nach des Sonntags "Plage"

Entheiligen doch die Wochentage.

\section{Der Lehrer}

Der Lehrer isł der gute Gärtner, Der in die Kinderherzen pflanzt

Den lichten, frohen Himmelsgarten,

In dem die Jugendseele tanzt.

Er hegt und pflegt die goldne Tugend

Und zeigt an all der Kindlein Hand

Im frohen Schritt, kaum merkt's die Jugend,

Den sichern Weg durchs Kinderland.

O Kindlein, sei ein treu Gefährte, Auf dass du fröhlich blühst und grünst! Vertrau ihm, der dich freundlich lehrte Erziehung ist ein Liebesdienst.

Karl Niederhut glaubte, das glückliche Zeitalter werde erst anbrechen, wenn alle Menschen ihre Herzen für einander geöffnet haben in Freundschaft und Hilfsbereitschaft. Er wünschte, dass alle Mächtigen gütig und alle Gütigen mächtig wären.

Wenn Menschenherzen für einander schlagen,

Welch selig Klingen, das kein Wind verweht!

$O$ ew'ger Klang, der in Aonen-Tagen

Im All verklingt und niemals untergeht.

Solch Zauberschlag ist heut der Welt vonnöten, Wo liebeleer Millionen Herzen klagen:

Komm, lass die Flammen jungen Morgen röten,

Das Fever uns zu leeren Herzen tragen!

\section{RESUMO}

Este artigo é uma contribuição à literatura teuto-brasileira. O escritor e poeta Karl Niederhut, um dos mais populares representantes 
das letras alemãs no Brasil, faleceu em Pôrto Alegre, com 91 anos, aos 29 de abril do corrente. Niederhut, natural de Hannover, Alemanha, chegou ao Brasil em 1913 e exerceu as seguintes atividades: professor no Estado de São Paulo, redator da "Deutsche Post" (Correio Alemão) em São Leopoldo, colaborador do semanário brasileiro "Brasil-Post", em São Paulo, e de quase todos os jornais e revistas em língua alemã na América Latina.

Escreveu uma peça teatral, apresentada por ocasião do primeiro centenário de imigração alemã no Brasil (1924), um drama com o título "A profetisa de Ferra Braz", poesias, sentenças, contos e artigos referentes à política, educação popular, homeopatia e comentários aos acontecimentos da vida diária. Nos últimos anos de sua vida dedicou-se a um romance, ainda inédito, cujos temas centrais são a população indígena e a história da colonização sul-americana.

Karl Niederhut era cristão com profunda fé em Deus, criador de todos os sêres. Influenciado pelas filosofias hindus e doutrina de Buda, chegou a reconhecer o valor do cristianismo, porém sem dogmas e credos. Enquanto a pergunta sôbre a natureza de Cristo para êle não foi importante, atribuiu à sucessão de Cristo a maior importância. Seu lema foi "Amarás o teu próximo como a ti mesmo", o qual praticou durante tôda sua vida. As atividades mais essenciais do homem foram para êle pensar e sentir. A obtenção de uma verdadeira humanidade, segundo o velho sábio Niederhut, exige um exercício constante para dominar e determinar os pensamentos. Pensamentos altos são orações permanentes, a atividade por excelência do homem e a melhor preparação para uma vida no além.

Os quatro pilares fundamentais na sua vida foram: fé, bondade, felicidade e saúde, que constantemente se encontram nas suas sentenças, versos humorísticos à maneira de Erich Kästner, Joachim Ringelnatz e Wilhelm Busch, os quais podemos unir sob o ciclo "Sabedoria alegre da vida".

A poesia de Niederhut faz soar sons e temas variados. Seus elementos polares de estrutura, na seqüência de imagens, são Deus homem, homem - Deus, homem - natureza, seus princípios básicos psíquicos são alegria, dor e gratidão. A lírica, como êle a vê, é oração permanente e ações de graças a Deus.

Kart Niederhut acreditou que a época feliz sòmente apontará, se todos os homens abrirem seus corações, um para o outro, em amizade e disposição recíproca de ajuda. Desejou que os poderosos sejam bondosos e todos os bondosos sejam poderosos. 